CLINICAL STUDY

\title{
Cortisol, DHEA sulphate, their ratio, and all-cause and cause-specific mortality in the Vietnam Experience Study
}

\author{
Anna C Phillips, Douglas Carroll, Catharine R Gale ${ }^{1}$, Janet M Lord ${ }^{2}$, Wiebke Arlt ${ }^{3}$ and G David Batty ${ }^{4}$ \\ School of Sport and Exercise Sciences, University of Birmingham, Birmingham B15 2TT, England, UK, ${ }^{1}$ MRC Epidemiology Resource Centre, University of \\ Southampton, Southampton SO1 7 1BJ, UK, ${ }^{2}$ School of Immunity and Infection, IMRC Centre for Immune Regulation, ${ }^{3}$ School of Clinical and Experimental \\ Medicine, Centre for Endocrinology, Diabetes and Metabolism, University of Birmingham, Birmingham B15 2TT, UK and ${ }^{4}$ MRC Social and Public Health \\ Sciences Unit, Glasgow 612 8QQ, UK
}

(Correspondence should be addressed to A C Phillips; Email: a.c.phillips@bham.ac.uk)

\begin{abstract}
Objectives: The aim of the present analyses was to examine the association between cortisol, DHEA sulphate (DHEAS) and the cortisol:DHEAS ratio and mortality.

Design: This was a prospective cohort analysis.

Methods: Participants were 4255 Vietnam-era US army veterans. From military service files, telephone interviews and a medical examination, occupational, socio-demographic and health data were collected. Contemporary morning fasted cortisol and DHEAS concentrations were determined. Mortality was tracked over the subsequent 15 years. The outcomes were all-cause, cardiovascular disease, cancer, other medical mortality and external causes of death. Cox proportional hazard models were tested, initially with adjustment for age, and then with adjustment for a range of candidate confounders.

Results: In general, cortisol concentrations did not show an association with all-cause or cause-specific mortality. However, in age-adjusted and fully adjusted analyses, DHEAS was negatively related to all-cause, all cancers and other medical mortality; high DHEAS concentrations were protective. The cortisol:DHEAS ratio was also associated with these outcomes in both age-adjusted and fully adjusted models; the higher the ratio, the greater the risk of death.

Conclusions: DHEAS was negatively associated, and the ratio of cortisol to DHEAS was positively associated with all-cause, cancer and other medical cause mortality. Further experimental study is needed to elucidate the mechanisms involved in these relationships.
\end{abstract}

European Journal of Endocrinology $163285-292$

\section{Introduction}

The corticosteroid hormone cortisol, a component of the hypothalamic-pituitary-adrenal (HPA) axis, has a key role in the stress response (1) and has some immunosuppressive effects (2). Higher circulating cortisol levels have been observed in critically ill intensive care patients (3), such as those experiencing septic shock and trauma (4). Another adrenal cortex hormone, DHEA, is a precursor to sex hormones and is present in the circulation, predominantly as its sulphated form DHEA sulphate (DHEAS). DHEA/DHEAS appears to counterbalance many of the negative effects of cortisol on immunity $(5,6)$. For example, it has been shown in vitro that higher cortisol suppresses neutrophil function, and this effect can be overcome by co-incubation with DHEAS $(7,8)$. Higher levels of DHEAS are also associated with less serious illness among intensive care patients $(3,4,9)$. Moreover, it appears that the activity of the HPA axis as reflected in the ratio of cortisol to DHEA is particularly important with regard to health. The production of DHEAS declines in older age, a phenomenon termed adrenopause, while the production of cortisol remains stable, resulting in higher cortisol:DHEA ratios. This altered ratio has been associated with the age-related loss of immunity (immunosenescence) $(2,7,10)$, as well as with nonimmunity-related psychological outcomes such as higher anxiety, mood disturbance, confusion and poorer cognitive performance (11).

In cohort studies, cortisol and DHEA levels have also been linked to mortality. For example, higher cortisol was associated with increased mortality in patients with heart failure (12), sepsis (13) and stroke (14), although this is not a universal finding (15). DHEAS has been shown to be negatively associated with total and cardiovascular disease mortality in selected studies, with ischaemic heart disease (16) in women, with 
all-cause mortality in men only $(17,18)$, and with both all-cause and cardiovascular disease mortality in older people (19) of both sexes (20). Other studies have found no association with either disease or all-cause mortality (21). Surprisingly, few studies have examined the cortisol:DHEA/S ratio in association with mortality. However, one study of septic shock and trauma patients revealed higher cortisol, lower DHEAS and a higher cortisol:DHEA ratio among those who were more seriously ill and non-survivors (4). The ratio also predicted all-cause mortality but not disease mortality in US men who had fought in Vietnam in the present sample (22). What is not known is whether serum cortisol and DHEAS alone could predict all-cause mortality in this sample, and whether cortisol, DHEAS and their ratio are associated with mortality from other causes such as cancer, other medical, and external causes. As cortisol, DHEAS and their ratio are associated with a variety of health outcomes, particularly immune-related measures $(7,10,23,24)$, it might be expected that they are related to death from particular causes. Consequently, the present analyses examined the association between cortisol, DHEAS, their ratio and all-cause, cardiovascular disease, cancer mortality, other medical causes and external causes of death in a substantial cohort of male military veterans.

\section{Materials and methods}

\section{Sample}

Participants $(n=4255)$ were identified retrospectively from data gathered as part of the Vietnam Experience Study; an epidemiological study commissioned by the US congress to investigate the health consequences of the military experiences of Vietnam veterans. Participants were male military personnel drawn from $\sim 5$ million US Vietnam-era Army veterans whose service files were stored at the National Personnel Records Center (25). The Centers for Disease Control, Atlanta, had access to US Veteran Administration records and provided the authors with a fully anonymised dataset. Ethical approval for the study was given by the various relevant bodies, including the US Centers for Disease Control. Eligibility criteria are published elsewhere, and the final cohort with complete data included 18313 former military personnel (25-27).

\section{Data collection}

Information pertaining to place of service and ethnicity was extracted from the military archives. Participants were designated as being Vietnam veterans if they had served at least one tour of duty in Vietnam, and as non-Vietnam veterans if they did not (this group included men who served one or more tours of duty in Korea, Germany or the US). The ethnic origin of the study members were classified as 'white', 'black' or 'other'; the latter group comprising Hispanics, Asians, Pacific Islanders, American Indians and Alaskan Natives. Of those included in the original cohort, 17867 were considered to be alive on December 31, 1983, and therefore were eligible for active follow-up. In 1985, the participants were invited to participate in a telephone interview. Of those traced $(n=16349)$, 15288 men were able to participate in the 1985 telephone survey $(85.6 \%$ of those alive on December 31 st 1983) (27). From the telephone survey, educational grade achieved at school $(\leq 11$ th grade, 12 th grade and $>12$ th grade) and household income in midlife $(\leq \$ 20 \mathrm{k},-\$ 40 \mathrm{k},>\$ 40 \mathrm{k}$ per year) were determined as measures of socio-economic status. Frequency of alcohol consumption (units per week), cigarette smoking habits and marital status were ascertained using standard questions. Participants were also asked whether or not they had a range of somatic physician-diagnosed health problems which included hypertension, cancer, diabetes and coronary heart disease $(28,29)$.

In 1986, a random sample of telephone interview respondents $(n=6443)$ were invited to attend a 3-day medical examination with orientation at a single facility in Albuquerque, New Mexico, for which travel expenses and a nominal stipend were paid; 4462 men who were representative of the original cohort attended the medical examination $(69.3 \%$ of those invited). The mean age at medical examination was 38.3 years (range: 31.1-49.0). The final number of participants with complete data after the medical examination was 4256. This group represents $23.3 \%$ of persons originally enrolled in the study. Serum cortisol and DHEAS were assayed in serum from a fasted blood sample using a double antibody RIA system (Leeco Diagnostics, Inc., Southfield, MI, USA). All laboratory assays were assured by using bench and blind repeat controls. The blind repeat tests were run for 1 in 20 randomly chosen samples; the correlations between first and repeat samples exceeded 0.98. Bench controls yielded intra- and inter-assay coefficients of variation that were all $<10 \%$. With the participant in a sitting position, a registered nurse using a standard mercury sphygmomanometer measured blood pressure twice consecutively, from both the arms. For analysis, an average of the two right arm systolic and diastolic blood pressure values was computed. Measurements from the left arm were used to verify individual results.

The vital status of men between army discharge and December 31st 1983 (the date the cohort was established) was ascertained by cross checking against a variety of mortality databases supplied by the US army, the Veterans Administration (Beneficiary Identification and Records Locator Subsystem), the Social Security Administration, the Internal Revenue Service and the National Center for Health Statistics (National Death Index). Vital status post medical examination continued 
to be ascertained until 31st December 2000 using the mortality databases described above. Mortality due to major cardiovascular disease (CVD) was classified using the International Classification of Diseases (ICD) (30) codes: ICD-9: 390-434 and 436-448, and ICD-10: I00-I78 which comprised acute rheumatic fever, chronic rheumatic heart diseases, hypertensive diseases, ischaemic heart diseases, pulmonary heart disease and diseases of pulmonary circulation, other forms of heart disease, cerebrovascular diseases, and diseases of arteries, arterioles and capillaries. The CVD mortality variable thus encompasses death from a variety of disorders; the bulk of the deaths were from ischaemic heart diseases. Mortality from cancer was classified using the ICD codes: ICD-9: 140-239 and ICD-10: C00-D48 which include malignant neoplasms of all specified areas, Hodgkin's disease, non-Hodgkin's lymphoma, leukaemia, multiple myeloma, immunoproliferative neoplasms and other malignant neoplasms of unspecified areas. Of all the cancers, the most frequent cause of death $(n=19)$ was from malignant neoplasms of the trachea, bronchus and lung. External causes of death included those coded as ICD-9: E800-E999 and ICD-10: V01-Y8, including accidents, suicide and homicide. Half of the deaths in this category were from suicide or homicide. Finally, 'other' causes of death were calculated as all-cause mortality minus the other classifications, and consisted of infectious diseases, liver diseases/failure, kidney diseases/failure and respiratory diseases. The most frequent causes of death in this category were from infection, including infection with HIV, and from liver disease. In the analyses reported below, 4255 men were included.

\section{Statistical analysis}

Owing to their skewed distribution, cortisol and DHEAS values were log transformed, as was the cortisol:DHEAS ratio. All covariates analysed in the study conformed to the assumption of proportional hazards over time; partial residuals were all randomly distributed. Having confirmed that the proportional hazards assumption had not been violated, Cox' proportional hazard regression was used to examine the relationships between cortisol, DHEAS, their ratio and mortality, in age-adjusted analyses. Demographic, military service, health behaviour and metabolic variables were compared using univariate Cox' proportional hazard regression between those who had and had not died. Further multivariate analyses of the relationships between cortisol, DHEAS, their ratio and mortality were then run, additionally adjusting for significant covariates, including some or all of place of service, ethnicity, marital status, alcohol consumption, smoking, household income and physical illness diagnosis. Only those covariates significant in the univariate prediction of mortality were included as covariates in the fully adjusted models.

\section{Results}

\section{All-cause mortality}

The arithmetic mean (s.D.) serum cortisol and DHEAS values for the whole sample were 18.2 (5.52) and $239.8(99.86) \mu \mathrm{g} / \mathrm{dl}$ respectively. This equates to 502.1 (152.30) and $832.1(346.51) \mathrm{nmol} / \mathrm{l}$ respectively. The mean (s.D.) cortisol to DHEAS ratio was 0.09 (0.06). During the 15 years of follow-up, there were 236 deaths. Table 1 shows the univariate predictions of all-cause mortality. Higher mortality was associated with service in Vietnam rather than with that in another overseas location, not being married, being non-white, smoking, having a physical illness, lower household income in midlife, higher systolic blood pressure (SBP) and higher alcohol consumption. Table 1 also shows the univariate hazard ratios (HRs) for cortisol, DHEAS and cortisol:DHEAS ratio predicting all-cause mortality. Age-adjusted analyses revealed that higher cortisol concentrations were associated with a higher all-cause mortality risk, $\mathrm{HR}=1.71,95 \%$ confidence interval $(\mathrm{CI})=1.12-2.62, P=0.013$. Conversely, those with higher DHEAS levels were at a decreased risk

Table 1 Univariate hazard ratios (HRs) (95\% confidence intervals (Cls)) predicting all-cause mortality.

\begin{tabular}{|c|c|c|}
\hline & \multicolumn{2}{|c|}{ All-cause mortality $(n=236)$} \\
\hline & $\mathrm{HR}(95 \% \mathrm{Cl})$ & $P$ \\
\hline $\begin{array}{l}\text { Age at medical } \\
\text { examination (years) }\end{array}$ & $1.04(0.99-1.09)$ & 0.13 \\
\hline Units of alcohol per week & $1.01(1.01-1.02)$ & $<0.001$ \\
\hline $\begin{array}{l}\text { Systolic blood pressure } \\
(\mathrm{mmHg})\end{array}$ & $1.02(1.01-1.03)$ & 0.001 \\
\hline Cortisol ( $\mu \mathrm{g} / \mathrm{dl})$ logged & $1.72(1.13-2.64)$ & 0.01 \\
\hline DHEAS $(\mu \mathrm{g} / \mathrm{dl})$ logged & $0.50(0.38-0.65)$ & $<0.001$ \\
\hline Cortisol:DHEAS logged & $2.07(1.63-2.64)$ & $<0.001$ \\
\hline \multicolumn{3}{|l|}{ Place of service } \\
\hline Other overseas & $0.71(0.51-0.98)$ & 0.04 \\
\hline US only & $0.76(0.53-1.08)$ & 0.12 \\
\hline Ever in Vietnam & Referent & - \\
\hline \multicolumn{3}{|l|}{ Ethnicity } \\
\hline Black & $2.28(1.67-3.13)$ & $<0.001$ \\
\hline Other & $1.88(1.22-2.92)$ & 0.004 \\
\hline White & Referent & - \\
\hline \multicolumn{3}{|l|}{ Household income in midlife } \\
\hline$<\$ 20000$ & $4.18(2.62-6.66)$ & $<0.001$ \\
\hline$-\$ 40000$ & $2.20(1.38-3.51)$ & 0.001 \\
\hline$>\$ 40000$ & Referent & Referent \\
\hline \multicolumn{3}{|l|}{ Smoking status } \\
\hline Current smoker & $2.01(1.43-2.83)$ & $<0.001$ \\
\hline Ex-smoker & $0.94(0.62-1.44)$ & 0.78 \\
\hline Non-smoker & Referent & Referent \\
\hline \multicolumn{3}{|l|}{ Marital status } \\
\hline Never married & $2.53(1.75-3.66)$ & $<0.001$ \\
\hline $\begin{array}{l}\text { Divorced/separated/ } \\
\text { widowed }\end{array}$ & $2.32(1.73-3.10)$ & $<0.001$ \\
\hline Married & Referent & Referent \\
\hline \multicolumn{3}{|l|}{ Physical illness* } \\
\hline Yes & $2.38(1.78-3.18)$ & $<0.001$ \\
\hline No & Referent & Referent \\
\hline
\end{tabular}

*Diabetes/hypertension/cancer or CHD. 
of death, $\mathrm{HR}=0.51,95 \% \mathrm{CI}=0.38-0.66, P<0.001$. The cortisol:DHEAS ratio was significantly related to mortality risk, $\mathrm{HR}=2.05,95 \% \mathrm{CI}=1.61-2.61$, $P<0.001$, such that individuals with a higher ratio were at a greater risk of death. Following adjustment for age and the other covariates collectively, the association between cortisol and mortality was no longer statistically significant at conventional levels $(\mathrm{HR}=1.32,95 \% \mathrm{CI}=0.86-2.03, P=0.20)$. However, higher DHEAS levels were still related to lower mortality risk, $\mathrm{HR}=0.55,95 \% \mathrm{CI}=0.43-0.71, P<0.001$, and the cortisol:DHEAS ratio remained significantly and positively associated with mortality, $\mathrm{HR}=1.76,95 \%$ $\mathrm{CI}=1.40-2.23, P<0.001$.

\section{Cardiovascular disease and cancer mortality}

Sixty-three participants died of CVD; Table 2 shows the HRs for the univariate predictors of CVD mortality. Participants who had died of CVD were slightly older; were more likely to have served in Vietnam than in another overseas location; were more likely to be divorced/widowed/separated, Black, smokers, in the lowest household income in midlife tertile; were more likely to have a physical illness, higher SBP, but were not likely to have higher alcohol consumption. Table 2 also presents the univariate HRs for cortisol, DHEAS and their ratio predicting CVD mortality status.
Age-adjusted analyses indicated that cortisol, DHEAS and the cortisol:DHEAS ratio were not associated with CVD mortality. The HRs for the univariate predictors of mortality from cancer are also presented in Table 2. Of the covariates tested, only age, presence of physical illness and smoking were significantly associated with death from cancer. There was no significant association between cortisol and cancer mortality. However, in ageadjusted models, higher DHEAS concentrations were associated with a reduced risk of death from cancer, $\mathrm{HR}=0.40,95 \% \mathrm{CI}=0.22-0.71, \quad P=0.002$, and a higher cortisol:DHEAS ratio was associated with an increased cancer mortality risk, $\mathrm{HR}=1.94$, 95\% $C I=1.13-3.34, P=0.02$. In the fully adjusted models, higher DHEAS concentrations were still related to lower mortality risk, $\mathrm{HR}=0.40,95 \% \mathrm{CI}=0.23-0.70$, $P=0.001$, and a higher cortisol:DHEAS ratio still associated with an increased risk of death from cancer, $\mathrm{HR}=2.04,95 \% \mathrm{CI}=1.19-3.48, P=0.01$.

\section{Non-medical causes and other causes of death}

The univariate HRs predicting death from non-medical causes are presented in Table 3. Those who died from non-medical causes had smaller household incomes in midlife. In the age-adjusted models, cortisol, DHEAS and their ratio were not associated with non-medical causes of death. The univariate predictions of mortality from

Table 2 Univariate hazard ratios (HRs) (95\% confidence intervals (Cls)) predicting mortality from CVD and cancer.

\begin{tabular}{|c|c|c|c|c|}
\hline & \multicolumn{2}{|c|}{ Died: CVD $(n=63)$} & \multicolumn{2}{|c|}{ Died: cancer $(n=47)$} \\
\hline & $\mathrm{HR}(95 \% \mathrm{Cl})$ & $P$ & $\mathrm{HR}(95 \% \mathrm{Cl})$ & $P$ \\
\hline Units of alcohol per week & $1.01(0.99-1.02)$ & 0.29 & $1.01(0.99-1.02)$ & 0.26 \\
\hline $\mathrm{SBP}(\mathrm{mmHg})$ & $1.03(1.02-1.05)$ & $<0.001$ & $1.02(0.99-1.04)$ & 0.10 \\
\hline Cortisol ( $\mu \mathrm{g} / \mathrm{dl})$ logged & $2.21(0.96-5.06)$ & 0.06 & $0.86(0.34-2.18)$ & 0.74 \\
\hline DHEAS ( $\mu \mathrm{g} / \mathrm{dl})$ logged & $0.77(0.44-1.35)$ & 0.36 & $0.37(0.21-0.64)$ & $<0.001$ \\
\hline Cortisol:DHEAS & $1.62(1.00-2.62)$ & 0.05 & $2.15(1.26-3.66)$ & 0.005 \\
\hline \multicolumn{5}{|l|}{ Place of service } \\
\hline Other overseas & $0.46(0.22-0.95)$ & 0.04 & $1.08(0.55-2.09)$ & 0.82 \\
\hline US only & $0.82(0.43-1.56)$ & 0.54 & $0.88(0.40-1.95)$ & 0.76 \\
\hline Ever in Vietnam & Referent & Referent & Referent & Referent \\
\hline \multicolumn{5}{|l|}{ Ethnicity } \\
\hline Black & $1.98(1.05-3.76)$ & 0.04 & $1.12(0.47-2.64)$ & 0.80 \\
\hline Other & $2.11(0.95-4.69)$ & 0.07 & $0.68(0.17-2.83)$ & 0.60 \\
\hline$<\$ 20000$ & $3.74(1.55-9.03)$ & 0.003 & $1.37(0.54-3.48)$ & 0.51 \\
\hline$-\$ 40000$ & $2.12(0.88-5.12)$ & 0.09 & $1.76(0.77-4.02)$ & 0.18 \\
\hline$>\$ 40000$ & Referent & Referent & Referent & Referent \\
\hline \multicolumn{5}{|l|}{ Smoking status } \\
\hline Current smoker & $2.14(1.07-4.30)$ & 0.03 & 3.49 (1.35-8.99) & 0.009 \\
\hline Ex-smoker & $1.35(0.61-3.00)$ & 0.47 & $1.97(0.69-5.67)$ & 0.21 \\
\hline Non-smoker & Referent & Referent & Referent & Referent \\
\hline \multicolumn{5}{|l|}{ Marital status } \\
\hline Never married & $1.40(0.59-3.30)$ & 0.44 & $0.54(0.13-2.23)$ & 0.42 \\
\hline Divorced/separated/widowed & $1.95(1.12-3.41)$ & 0.02 & $1.36(0.69-2.69)$ & 0.37 \\
\hline Married & Referent & Referent & Referent & Referent \\
\hline \multicolumn{5}{|l|}{ Physical illness* } \\
\hline Yes & $3.60(2.14-6.04)$ & $<0.001$ & $2.05(1.04-4.02)$ & 0.04 \\
\hline No & Referent & Referent & Referent & Referent \\
\hline
\end{tabular}

*Diabetes/hypertension/cancer or CHD. 
Table 3 Univariate hazard ratios (HRs) (95\% confidence intervals $(\mathrm{Cls})$ ) predicting mortality from external and other causes.

\begin{tabular}{|c|c|c|c|c|}
\hline & \multicolumn{2}{|c|}{ Died: external $(n=63)$} & \multicolumn{2}{|c|}{ Died: other $(n=47)$} \\
\hline & $\mathrm{HR}(95 \% \mathrm{Cl})$ & $P$ & $\mathrm{HR}(95 \% \mathrm{Cl})$ & $P$ \\
\hline Age at medical examination (years) & $0.93(0.83-1.04)$ & 0.20 & $0.98(0.89-1.07)$ & 0.64 \\
\hline Units of alcohol per week & $1.01(0.99-1.02)$ & 0.19 & $1.02(1.01-1.02)$ & $<0.001$ \\
\hline SBP $(\mathrm{mmHg})$ & $0.98(0.96-1.01)$ & 0.14 & $1.02(1.00-1.04)$ & 0.02 \\
\hline Cortisol $(\mu \mathrm{g} / \mathrm{dl})$ logged & $1.86(0.74-4.66)$ & 0.18 & $2.08(0.98-4.45)$ & 0.06 \\
\hline DHEAS $(\mu \mathrm{g} / \mathrm{dl})$ logged & $0.76(0.40-1.41)$ & 0.38 & $0.34(0.22-0.53)$ & $<0.001$ \\
\hline Cortisol:DHEAS & $1.54(0.90-2.63)$ & 0.11 & $2.95(1.98-4.40)$ & $<0.001$ \\
\hline \multicolumn{5}{|l|}{ Place of service } \\
\hline Other overseas & $0.57(0.27-1.18)$ & 0.13 & $0.84(0.49-1.46)$ & 0.54 \\
\hline US only & $0.68(0.31-1.46)$ & 0.32 & $0.69(0.36-1.32)$ & 0.26 \\
\hline Ever in Vietnam & Referent & Referent & Referent & Referent \\
\hline \multicolumn{5}{|l|}{ Ethnicity } \\
\hline Black & $1.08(0.46-2.55)$ & 0.86 & $5.03(3.08-8.21)$ & $<0.001$ \\
\hline Other & $1.65(0.65-4.18)$ & 0.29 & $3.07(1.49-6.33)$ & 0.002 \\
\hline White & Referent & Referent & Referent & Referent \\
\hline \multicolumn{5}{|l|}{ Household income in midlife } \\
\hline$<\$ 20000$ & $4.57(1.60-13.20)$ & 0.005 & $9.35(3.37-25.94)$ & $<0.001$ \\
\hline$-\$ 40000$ & $2.63(0.91-7.59)$ & 0.07 & $2.63(0.91-7.59)$ & 0.07 \\
\hline$>\$ 40000$ & Referent & Referent & Referent & Referent \\
\hline \multicolumn{5}{|l|}{ Smoking status } \\
\hline Current smoker & $1.87(0.89-3.93)$ & 0.10 & $1.60(0.93-2.73)$ & 0.09 \\
\hline Ex-smoker & $1.20(0.50-2.84)$ & 0.68 & $0.30(0.12-0.75)$ & 0.01 \\
\hline Non-smoker & Referent & Referent & Referent & Referent \\
\hline \multicolumn{5}{|l|}{ Marital status } \\
\hline Never married & $1.97(0.87-4.47)$ & 0.10 & $7.92(4.41-14.22)$ & $<0.001$ \\
\hline Divorced/separated/widowed & $1.57(0.81-3.05)$ & 0.18 & $5.26(3.08-9.00)$ & $<0.001$ \\
\hline Married & Referent & Referent & Referent & Referent \\
\hline \multicolumn{5}{|l|}{ Physical illness* } \\
\hline Yes & $1.61(0.81-3.22)$ & 0.17 & $2.26(1.35-3.82)$ & 0.002 \\
\hline No & Referent & Referent & Referent & Referent \\
\hline
\end{tabular}

*Diabetes/hypertension/cancer or CHD.

other causes are also summarised in Table 3. Those who died from other causes were more likely to be smokers, consumed more alcohol, had higher blood pressure, were less likely to be white, had a lower household income in midlife, and were less likely to be married and more likely to have a diagnosed chronic illness. In the age-adjusted and fully adjusted models, cortisol was not associated with other causes of death, but DHEAS was again protective, $\mathrm{HR}=0.33,95 \%$ CI $0.21-0.51$, $P<0.001$, and $\mathrm{HR}=0.45,95 \%$ CI $0.30-0.67$, $P<0.001$ respectively. A higher cortisol:DHEAS ratio was related to an increased risk of death by other causes in the age-adjusted models, $\mathrm{HR}=3.11,95 \% \mathrm{CI}$ 2.07-4.66, $P<0.001$, and in the fully adjusted models, $\mathrm{HR}=2.11,95 \% \mathrm{CI} 1.46-3.06, P<0.001$. In the fully adjusted models, the other predictors of death from other causes were smoking, high alcohol consumption, high resting SBP, not being married, not being white, low income in midlife and pre-existing physical illness.

\section{Discussion}

In a population of male Vietnam-era war veterans, the age-adjusted and fully adjusted analyses showed that DHEAS was associated with a reduced risk of all-cause, cancer and other-cause mortality. A higher cortisol:DHEAS ratio was associated with an increased risk of death from all causes, cancer and other causes. DHEAS and the cortisol:DHEAS ratio were not associated with death from cardiovascular disease or non-medical causes. For the most part, cortisol concentrations did not predict mortality. Although there was a positive association between cortisol and all-cause mortality in the analysis that adjusted only for age, this was attenuated to non-significance in the fully adjusted model.

These findings are concordant with those of previous studies where DHEAS has been shown to be protective against all-cause mortality in a variety of populations (17-20). Although negative associations between DHEAS concentrations and cardiovascular disease mortality have been reported $(20,31)$, which was not evident in the present sample, it is possible that this was a result of the older age (64 years + ) of the participants in the previous studies, who would have naturally decreased DHEAS levels associated with ageing (32). Only one study has demonstrated an association between DHEAS and cardiovascular mortality in men aged 30-80 years (33). In others, the association between DHEAS levels and cardiovascular disease mortality was lost after adjustment for a range of CVD risk factors (34). Of the few studies examining the cortisol:DHEAS ratio and total mortality, our findings confirm previous links (4). The failure of 
cortisol alone to predict mortality contrasts with some previous findings (12-14), but is in agreement with others $(9,15)$. As we stated above, DHEAS decreases with age (32), thus increasing the relative levels of cortisol, so it is possible that cortisol influences mortality in older populations as opposed to middleaged populations.

The extension to the literature that the present study provides is the evidence of associations with cancer and other-cause mortality for both DHEAS and the cortisol:DHEAS ratio. These findings are not surprising given that the majority of other medical causes of death were largely infectious and immune (e.g. HIV) diseases, and that both cortisol and DHEA/DHEAS have been proposed to have a role in regulating immune function $(5,10,23,24)$; DHEA/DHEAS is also considered protective against the immunosuppressive actions of cortisol (7). There is also evidence that treatment with DHEA can enhance immune function in humans with low DHEA/DHEAS levels (35), and increase immune function in animals $(36,37)$, although the benefits of DHEA supplementation on immunity in general remain controversial $(6,38,39)$. Taken together, the data suggest that DHEA might contribute to mortality via immune function effects. Although we grouped malignancy subtypes that do not have a unifying aetiology into a single category, in general cancer is similarly an immune-regulated disease (see e.g. (40)), and links are evident between an altered HPA axis and inflammation in cancer patients (41). It has also been suggested that low DHEA/S levels are associated with the initiation of cancer (42), suggesting a possible pathway by which lower DHEA/S concentrations and a higher cortisol:D$\mathrm{HEA} / \mathrm{S}$ ratio could relate to cancer mortality.

It is perhaps not surprising that externally caused mortality was not significantly related to cortisol, DHEAS or the cortisol:DHEAS ratio in this sample, given that it is difficult to conceive of mechanisms by which the altered levels of such hormones would increase the likelihood of death from suicide, homicide or accidents.

It is possible that the stress of army service could also contribute to neuroendocrine changes that in turn contribute to future morbidity and to the exacerbation of current disease, resulting in earlier mortality in this particular population. Others have suggested that inadequate adrenal functioning may be related to both psychological reactions due to exposure to the stress of war and the biological vulnerability to disease (43). Indeed, chronic stress has been associated with alterations in HPA axis function (44) and changes in leukocyte trafficking and function (Chrousos 1995). However, the mechanisms by which such stress-induced changes might relate to premature mortality are likely to be complex and diverse.

The present study has a number of limitations. First, in observational studies it is not possible to determine causality. It is possible that lower DHEAS and a high
cortisol:DHEAS ratio may be markers for some or several unmeasured factors related to mortality, rather than a cause per se. For example, a high cortisol:DHEAS ratio might result from extant disease. Low DHEA secretion, for example, is frequently observed in patients with an adrenal cortisol-producing adenoma. However, the present findings for DHEAS and the cortisol:DHEAS ratio survived adjustment for a pre-existing diagnosis of cancer, diabetes and heart disease, and the circulating cortisol levels measured in this cohort are not unusually elevated, nor is DHEAS unusually attenuated. Nevertheless, experimental studies would be necessary to establish a causal relationship. Secondly, the sample consisted exclusively of men, so these findings cannot be readily generalised to women. However, given that premenopausal women have lower circulating DHEAS (45), it is possible that the relationship between cortisol:DHEAS ratio and mortality in women might be even stronger. Thirdly, this study only used a single morning measurement of serum cortisol and DHEAS. Cortisol has a diurnal rhythm which would be best captured through multiple measurements. However, the timing of the present samples was for the most part invariant across the participants. Furthermore, DHEAS concentrations remain stable throughout the day and reflect the 24-h secretion of DHEA $(46,47)$.

In conclusion, in a sample of male Vietnam-era war veterans, lower DHEAS and a higher cortisol:DHEAS ratio were associated with an increased risk of all-cause, cancer and other-cause mortality. Furthermore, experimental studies would be necessary to elucidate mechanisms further and establish causality. It would be particularly instructive to examine the effects of DHEA supplementation in individuals with lower DHEA/S levels and/or high cortisol:DHEA/S ratios on mortality.

\section{Declaration of interest}

The authors declare that there is no conflict of interest that could be perceived as prejudicing the impartiality of the research reported.

\section{Funding}

This research did not receive any specific grant from any funding agency in the public, commercial or not-for-profit sector.

\section{References}

1 Ockenfels MC, Porter L, Smyth J, Kirschbaum C, Hellhammer DH \& Stone AA. Effect of chronic stress associated with unemployment on salivary cortisol: overall cortisol levels, diurnal rhythm, and acute stress reactivity. Psychosomatic Medicine $1995 \mathbf{5 7}$ 460-467.

2 Bauer ME, Jeckel CM \& Luz C. The role of stress factors during aging of the immune system. Annals of the New York Academy of Sciences 20091153 139-152. 
3 Wade CE, Lindberg JS, Cockrell JL, Lamiell JM, Hunt MM, Ducey J \& Jurney TH. Upon-admission adrenal steroidogenesis is adapted to the degree of illness in intensive care unit patients. Journal of Clinical Endocrinology and Metabolism 198867 223-227.

4 Arlt W, Hammer F, Sanning P, Butcher SK, Lord JM, Allolio B, Annane D \& Stewart PM. Dissociation of serum dehydroepiandrosterone and dehydroepiandrosterone sulfate in septic shock. Journal of Clinical Endocrinology and Metabolism $2006 \mathbf{9 1}$ $2548-2554$.

5 Sacco M, Valenti G, Corvi Mora P, Wu FC \& Ray DW. DHEA, a selective glucocorticoid receptor antagonist: its role in immune system regulation and metabolism. Journal of Endocrinological Investigation $2002 \mathbf{2 5} 81-82$.

6 Hazeldine J, Arlt W \& Lord JM. Dehydroepiandrosterone as a regulator of immune cell function. Journal of Steroid Biochemistry and Molecular Biology $2010 \mathbf{1 2 0} 127-136$.

7 Butcher SK, Killampalli V, Lascelles D, Wang K, Alpar EK \& Lord JM. Raised cortisol:DHEAS ratios in the elderly after injury: potential impact upon neutrophil function and immunity. Aging Cell 20054 319-324.

8 Radford DJ, Wang K, McNelis JC, Taylor AE, Hechenberger G, Hofmann J, Chahal H, Arlt W \& Lord JM. Dehdyroepiandrosterone sulfate directly activates protein kinase $C-\beta$ to increase human neutrophil superoxide generation. Molecular Endocrinology 201024 813-821.

9 Dimopoulou I, Stamoulis K, Ilias I, Tzanela M, Lyberopoulos P, Orfanos S, Armaganidis A, Theodorakopoulou M \& Tsagarakis S. A prospective study on adrenal cortex responses and outcome prediction in acute critical illness: results from a large cohort of 203 mixed ICU patients. Intensive Care Medicine 200733 $2116-2121$.

10 Buford TW \& Willoughby DS. Impact of DHEA(S) and cortisol on immune function in aging: a brief review. Applied Physiology, Nutrition, and Metabolism 200833 429-433.

11 van Niekerk JK, Huppert FA \& Herbert J. Salivary cortisol and DHEA: association with measures of cognition and well-being in normal older men, and effects of three months of DHEA supplementation. Psychoneuroendocrinology $2001 \mathbf{2 6}$ 591-612.

12 Guder G, Bauersachs J, Frantz S, Weismann D, Allolio B, Ertl G, Angermann CE \& Stork S. Complementary and incremental mortality risk prediction by cortisol and aldosterone in chronic heart failure. Circulation 2007115 1754-1761.

13 Sam S, Corbridge TC, Mokhlesi B, Comellas AP \& Molitch ME. Cortisol levels and mortality in severe sepsis. Clinical Endocrinology 200460 29-35.

14 Christensen H, Boysen G \& Johannesen HH. Serum-cortisol reflects severity and mortality in acute stroke. Journal of Neurological Sciences 2004217 175-180.

15 Van den Berghe G, Baxter RC, Weekers F, Wouters P, Bowers CY, Iranmanesh A, Veldhuis JD \& Bouillon R. The combined administration of GH-releasing peptide-2 (GHRP-2), TRH and GnRH to men with prolonged critical illness evokes superior endocrine and metabolic effects compared to treatment with GHRP-2 alone. Clinical Endocrinology 200256 655-669.

16 Haffner SM, Moss SE, Klein BE \& Klein R. Sex hormones and DHEA-SO $\mathrm{S}_{4}$ in relation to ischemic heart disease mortality in diabetic subjects. The Wisconsin Epidemiologic Study of Diabetic Retinopathy. Diabetes Care 199619 1045-1050.

17 Berr C, Lafont S, Debuire B, Dartigues JF \& Baulieu EE. Relationships of dehydroepiandrosterone sulfate in the elderly with functional, psychological, and mental status, and short-term mortality: a French community-based study. PNAS 199693 13410-13415.

18 Mazat L, Lafont S, Berr C, Debuire B, Tessier JF, Dartigues JF \& Baulieu EE. Prospective measurements of dehydroepiandrosterone sulfate in a cohort of elderly subjects: relationship to gender, subjective health, smoking habits, and 10-year mortality. PNAS 200198 8145-8150.
19 Trivedi DP \& Khaw KT. Dehydroepiandrosterone sulfate and mortality in elderly men and women. Journal of Clinical Endocrinology and Metabolism 200186 4171-4177.

20 Glei DA \& Goldman N. Dehydroepiandrosterone sulfate (DHEAS) and risk for mortality among older Taiwanese. Annals of Epidemiology 200616 510-515.

21 Tilvis RS, Kahonen M \& Harkonen M. Dehydroepiandrosterone sulfate, diseases and mortality in a general aged population. Aging 199911 30-34.

22 Boscarino JA. Psychobiologic predictors of disease mortality after psychological trauma: implications for research and clinical surveillance. Journal of Nervous and Mental Disease 2008196 100-107.

23 Araneo B \& Daynes R. Dehydroepiandrosterone functions as more than an antiglucocorticoid in preserving immunocompetence after thermal injury. Endocrinology 1995136 393-401.

24 Arlt W. Quality of life in Addison's disease - the case for DHEA replacement. Clinical Endocrinology 200256 573-574.

25 The Centers for Disease Control Vietnam Experience Study. Postservice mortality among Vietnam veterans. Journal of the American Medical Association 1987257 790-795.

26 Boehmer TK, Flanders WD, McGeehin MA, Boyle C \& Barrett DH. Postservice mortality in Vietnam veterans: 30-year follow-up. Archives of Internal Medicine 2004164 1908-1916.

27 Batty GD, Shipley MJ, Mortensen L, Boyle SH, Barefoot J, Grønbaek M, Gale CR \& Deary IJ. IQ in late adolescence/early adulthood, risk factors in middle-age, and later all-cause mortality in men: the Vietnam Experience Study. Journal of Epidemiology and Community Health $200862522-531$.

28 The Centers for Disease Control Vietnam Experience Study. Health status of Vietnam veterans. I. Psychosocial characteristics. Journal of the American Medical Association 1988259 2701-2707.

29 The Centers for Disease Control Vietnam Experience Study. Health status of Vietnam veterans. II. Physical Health. Journal of the American Medical Association $19882592708-2714$.

30 World Health Organisation. International Statistical Classification of Diseases and Related Health Problems. Geneva: WHO, 1992.

31 Barrett-Connor E, Khaw KT \& Yen SS. A prospective study of dehydroepiandrosterone sulfate, mortality, and cardiovascular disease. New England Journal of Medicine 1986315 1519-1524.

32 Bauer ME. Stress, glucocorticoids and ageing of the immune system. Stress $2005 \mathbf{8} 69-83$.

33 Barrett-Connor E \& Goodman-Gruen D. The epidemiology of DHEAS and cardiovascular disease. Annals of the New York Academy of Sciences 1995774 259-270.

34 LaCroix AZ, Yano K \& Reed DM. Dehydroepiandrosterone sulfate, incidence of myocardial infarction, and extent of atherosclerosis in men. Circulation 199286 1529-1535.

35 Khorram O, Vu L \& Yen SS. Activation of immune function by dehydroepiandrosterone (DHEA) in age-advanced men. Journals of Gerontology. Series A, Biological Sciences and Medical Sciences 1997 52 M1-M7.

36 Danenberg HD, Ben-Yehuda A, Zakay-Rones Z \& Friedman G. Dehydroepiandrosterone (DHEA) treatment reverses the impaired immune response of old mice to influenza vaccination and protects from influenza infection. Vaccine 199513 1445-1448.

37 Weksler ME. Immune senescence and adrenal steroids: immune dysregulation and the action of dehydroepiandrosterone (DHEA) in old animals. European Journal of Clinical Pharmacology $1993 \mathbf{4 5}$ (Suppl 1) S21-S23 (discussion S43-S44).

38 Araneo B, Dowell T, Woods ML, Daynes R, Judd M \& Evans T. DHEAS as an effective vaccine adjuvant in elderly humans. Proofof-principle studies. Annals of the New York Academy of Sciences $1995774232-248$.

39 Ben-Yehuda A, Danenberg HD, Zakay-Rones Z, Gross DJ \& Friedman G. The influence of sequential annual vaccination and of DHEA administration on the efficacy of the immune response to influenza vaccine in the elderly. Mechanisms of Ageing and Development $1998 \mathbf{1 0 2} 299-306$.

40 Loose D \& Van de Wiele C. The immune system and cancer. Cancer Biotherapy and Radio Pharmaceuticals 200924 369-376. 
41 Miller AH, Ancoli-Israel S, Bower JE, Capuron L \& Irwin MR. Neuroendocrine-immune mechanisms of behavioral comorbidities in patients with cancer. Journal of Clinical Oncology 200826 971-982.

42 Howard JM. Common factor of cancer and the metabolic syndrome may be low DHEA. Annals of Epidemiology 200717270.

43 Boscarino JA. Posttraumatic stress disorder and physical illness: results from clinical and epidemiologic studies. Annals of the New York Academy of Sciences 20041032 141-153.

44 Raison CL \& Miller AH. When not enough is too much: the role of insufficient glucocorticoid signaling in the pathophysiology of stress-related disorders. American Journal of Psychiatry 2003160 $1554-1565$.

45 Orentreich N, Brind JL, Rizer RL \& Vogelman JH. Age changes and sex differences in serum dehydroepiandrosterone sulfate concentrations throughout adulthood. Journal of Clinical Endocrinology and Metabolism 198459 551-555.
46 Arlt W, Justl HG, Callies F, Reincke M, Hubler D, Oettel M, Ernst M Schulte HM \& Allolio B. Oral dehydroepiandrosterone for adrenal androgen replacement: pharmacokinetics and peripheral conversion to androgens and estrogens in young healthy females after dexamethasone suppression. Journal of Clinical Endocrinology and Metabolism $1998 \mathbf{8 3}$ 1928-1934.

47 Arlt W, Haas J, Callies F, Reincke M, Hubler D, Oettel M, Ernst M, Schulte HM \& Allolio B. Biotransformation of oral dehydroepiandrosterone in elderly men: significant increase in circulating estrogens. Journal of Clinical Endocrinology and Metabolism $1999 \mathbf{8 4}$ $2170-2176$.

Received 19 May 2010

Accepted 24 May 2010 